\section{Pulmonary Artery Compression by a Bronchogenic Cyst Simulating Congenital Pulmonary Artery Stenosis}

\author{
WILLIAM J. WATTS, MD \\ HAROLD H. ROTMAN, MD \\ GREGG A. PATTEN, MD
}

Congenital pulmonary artery (PA) stenosis is a rare congenital heart defect. In most cases there is an antecedent history of maternal rubella. ${ }^{1}$ Acquired PA stenosis results from compression and narrowing of $\geq 1$ major PAs by an extrinsic process. Acquired PA stenosis is most often the result of a benign or malignant thoracic

From the University of Michigan Medical Center, 1405 E. Ann Street, Ann Arbor, Michigan 48109. This study was supported in part by a grant from the Michigan Lung Association. Manuscript received March 30, 1983; revised manuscript received July 5, 1983, accepted July 8, 1983. neoplasm, sarcoidosis, mediastinal fibrosis or aortic aneurysm. We report a patient with long standing PA compression due to a mediastinal bronchogenic cyst.

$D S$, a 21-year-old woman admitted to the hospital because of dyspnea and pleuritic chest pain for 5 days, had the diagnosis of congenital right PA stenosis since age 6 years, when a systolic precordial murmur was noted. Cardiac catheterization in childhood showed isolated mild right PA stenosis; the mean pressure in the pulmonary trunk was 30 $\mathrm{mm} \mathrm{Hg}$, and the mean right $P A$ pressure was $15 \mathrm{~mm} \mathrm{Hg}$. She remained well during the subsequent 15 years. On the current admission, examination disclosed a systolic ejection murmur at the left sternal border. The electrocardiogram was normal. A pulmonary perfusion scan (Fig. 1) and pulmonary angiogram showed absent perfusion of the right lung. Chest computerized tomography (Fig. 2) showed a subcarinal mass thought to be a bronchogenic cyst (confirmed histologically). Thoracotomy disclosed a 5-cm subcarinal cyst that compressed the right main PA. Intraoperative resection of the cyst yielded an immediate palpable return of blood flow to the right $P A$. A repeat perfusion scan (Fig. 1) showed normal perfusion to the right and left lungs 3 days after thoracotomy. The precordial systolic murmur was absent after operation.
FIGURE 1. Pulmonary perfusion scans showing complete obstruction of right pulmonary artery (August 25, 1982), which is completely relieved after resection of the bronchogenic cyst (September 10, 1982).

FIGURE 2. Chest computerized tomogram before surgery showing a subcarinal bronchogenic cyst.
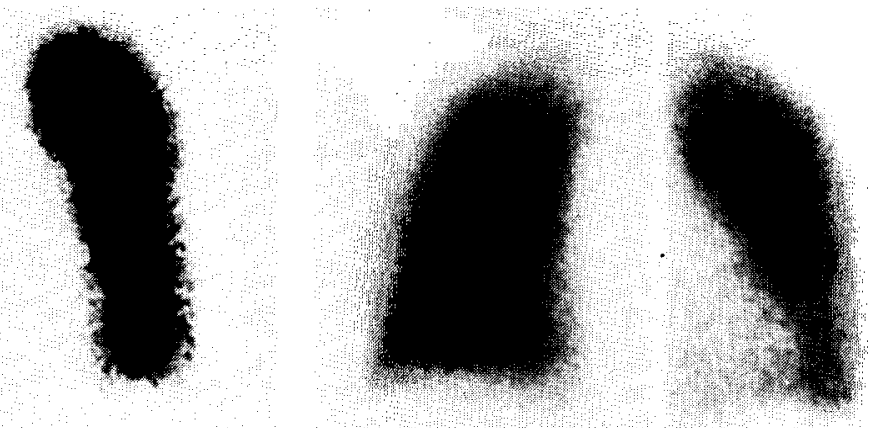

\section{Aug. 25,1982 Sept. 10,1982}

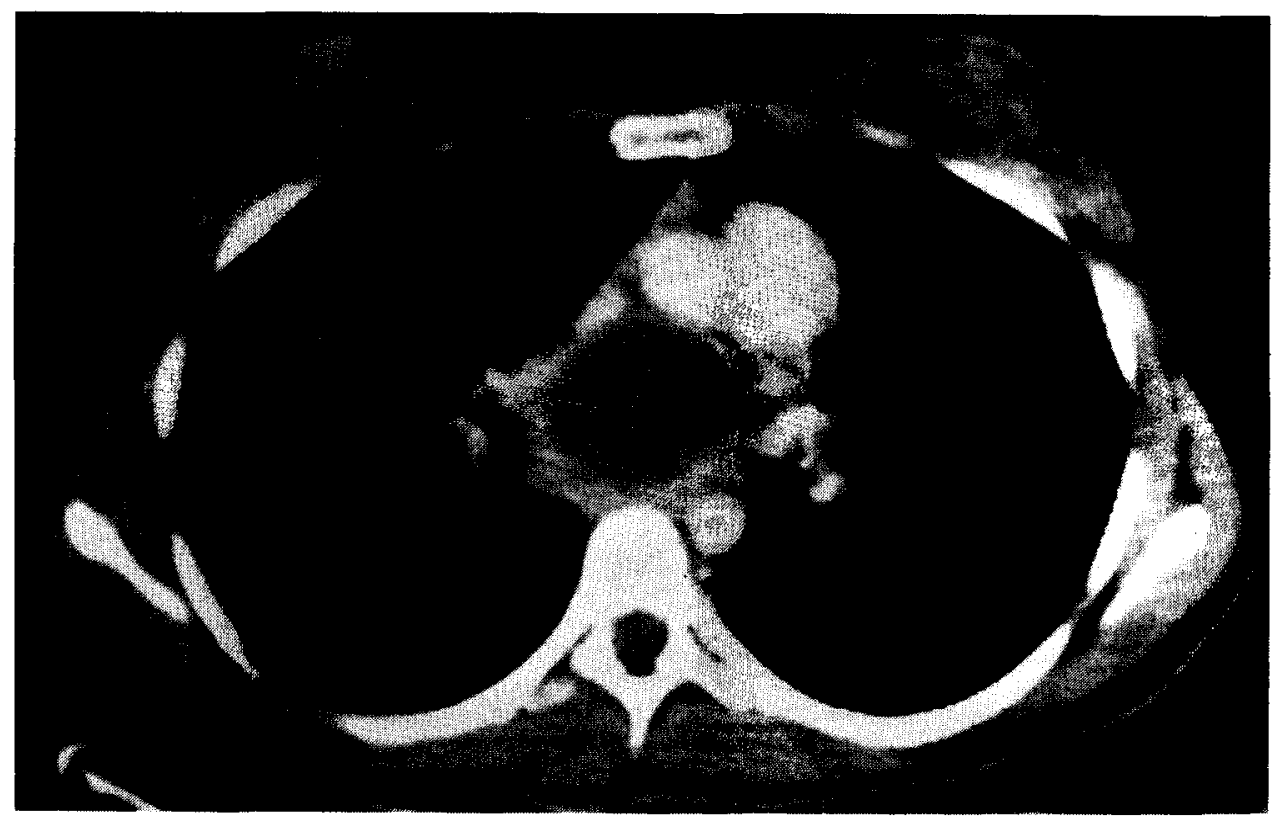


This patient is the third case described of acquired PA stenosis caused by a bronchogenic cyst. ${ }^{2,3}$ In the present case, a bronchogenic cyst caused stable, longstanding compression of the right PA. During child hood, cardiac catheterization "confirmed" the diagnosis of "congenital" PA stenosis. Only when the cyst caused total occlusion of the right PA, 15 years later, did symptoms develop and the cause of the PA stenosis become apparent. The symptoms and signs our patient had are typical of acquired PA stenosis: Chest pain occurs in three fourths of patients, dyspnea in over half, and a pulmonary systolic ejection murmur in almost all patients. ${ }^{4}$

The diagnosis of acquired PA stenosis was suggested in our patient by pulmonary perfusion scanning; pul- monary arteriography was diagnostic. Chest comput erized tomography was useful in our case; the characteristic subcarinal location, high tissue density and homogeneous appearance were very suggestive of a mediastinal bronchogenic cyst. ${ }^{5}$

\section{References}

1. Venables AW. The syndrome of pulmonary artery stenosis complicating maternal rubella. Br Med J 1965;27:49-55.

2. Miller DC, Walter JP, Guthaner DF, Mark JBD. Recurrent mediastinal bronchogenic cyst. Chest 1978;74:218-220.

3. Harris M, Woo-Ming Wo, Miller CG. Acquired puimonary stenosis due to compression by a bronchogenic cyst. Thorax 1973;28;394-398.

4. Littler WA, Meade JB, Hamilton DI. Acquired pulmonary stenosis. Thorax 1970;25:465-471

5. Nakata H, Nakayama C, Kimoto T, Nakayama T, Tsukamoto $Y$, Nobe $T$, Suzuki H. Computed tomography of mediastinal bronchogenic cysts. J Comput Assist Tomogr 1982;6:733-738.

\section{Coexistence of Ductal and Systemic Pulmonary Arterial Supply in Pulmonary Atresia with Ventricular Septal Defect}

\author{
CARLA FRESCURA, MD \\ ENRICO TALENTI, MD \\ PIERO A. PELLEGRINO, MD \\ ALESSANDRO MAZZUCCO, MD \\ GIUSEPPE FAGGIAN, MD \\ GAETANO THIENE, MD
}

In pulmonary atresia with ventricular septal defect (VSD), the ductus arteriosus and the systemic collateral arteries are the sources of blood supply to the lungs. ${ }^{1-3}$ In previous anatomic studies, the 2 sources appeared mutually exclusive; that is, when the ductus arteriosus persists, no systemic arteries supply the same lung. ${ }^{4} \mathrm{We}$ report here a case of pulmonary atresia with VSD in which this rule apparently failed.

A 40-day-old infant was admitted for cyanosis and respiratory distress, and shortly thereafter died. At autopsy, the heart was in situs solitus with levocardia, the venous drainages were normal, and the atrioventricular connections concordant. The pulmonary trunk and the left pulmonary artery were absent (Fig. 1a). The aorta arose above a large "perimembranous" VSD, which was in fibrous continuity with both mitral and tricuspid valves. The pulmonary outflow tract was atretic and no infundibulum was identified. The aortic arch was left-sided, and gave origin to an intrapericardial artery that continued with the right pulmonary artery. $A$ large collateral artery that arose from the distal descending thoracic aorta entered the left pulmonary hylum behind the bronchus (Fig. 2). Another collateral artery took origin from the proximal descending thoracic aorta and reached the upper lobe of the right lung, after a retro-

From the Departments of Pediatrics, Radiology, Cardiovascular Surgery and Pathology, University of Padua, Medical School, Padua, Italy. This study was supported by Consiglio Nazionale delle Ricerche, Rome, and by Opera Martino Arrigoni, Belluno, Italy. Manuscript received March 1, 1983; revised manuscript received July 27, 1983, accepted August $5,1983$. esophageal course (Fig. 2). Injection of contrast material into the left collateral artery opacified a normally branching intraparenchymal pulmonary artery (Fig. $3 a$ ). On the other side, injection through the right collateral artery opacified only the apex of the right upper lobe (Fig. 3a). Histologic study disclosed that the proximal right pulmonary artery

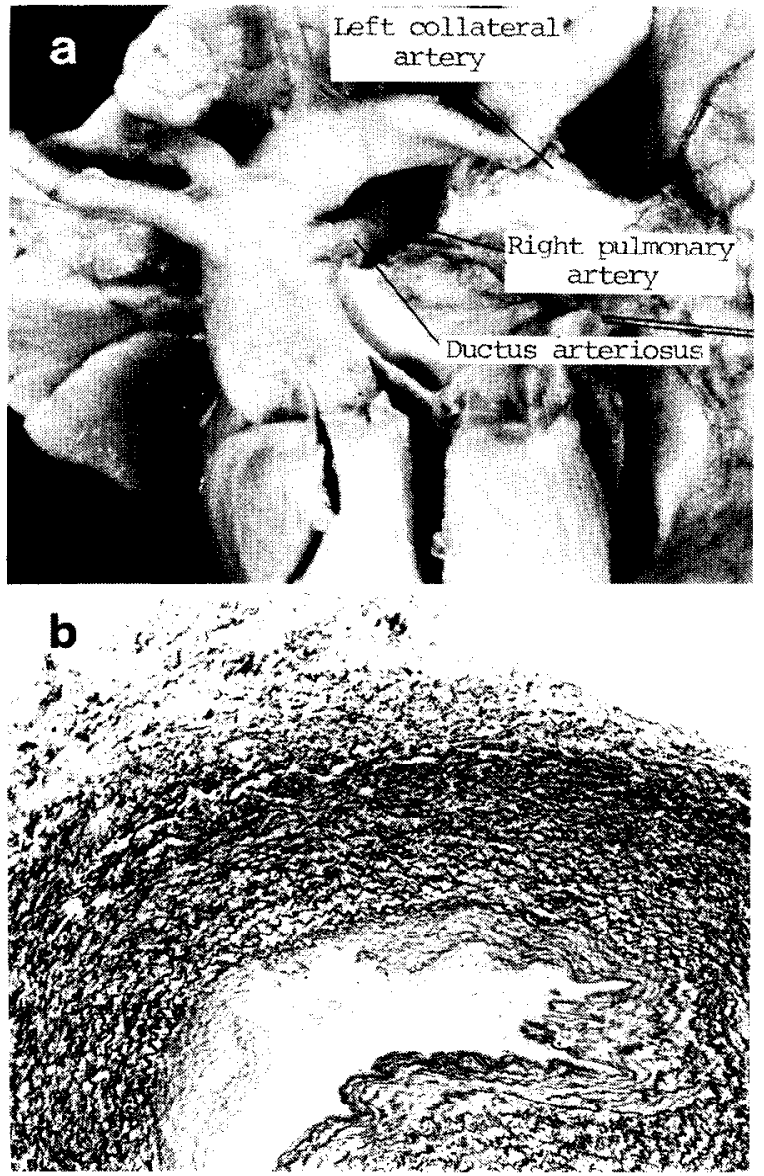

FIGURE 1. a, gross view of the heart and lung specimen. The pulmonary trunk and the left pulmonary artery are absent and the aortic arch is left-sided. A ductus arteriosus gives origin to the right pulmonary artery. b, histology of the ductus arteriosus: Note intimal cushions as typical features of a ductal structure. Weigert-Van Gieson stain; original magnification $\times 15$, reduced $28 \%$. 